\title{
TOWARDS THE SUSTAINABLE MANAGEMENT OF AIR QUALITY AND HUMAN EXPOSURE: EXEMPLARY CASE STUDIES
}

\author{
MARCO SCHIAVON ${ }^{1}$, MARCO RAGAZZI $^{1}$, ELENA CRISTINA RADA ${ }^{1,2}$, \\ ELENA MAGARIL ${ }^{3} \&$ VINCENZO TORRETTA $^{2}$ \\ ${ }^{1}$ Department of Civil, Environmental and Mechanical Engineering, University of Trento, Italy \\ ${ }^{2}$ Department of Theoretical and Applied Sciences, Insubria University, Italy \\ ${ }^{3}$ Department of Environmental Economics, Ural Federal University, Russian Federation
}

\begin{abstract}
This paper presents an overview of various situations that may lead to critical levels of human exposure to different air pollutants and that are often underestimated by the people and the environmental legislation. After an overview on indoor activities that contribute to generate high levels of exposure to particulate matter, inorganic and organic pollutants (including carcinogenic compounds), the paper focuses on outdoor critical contexts that are not adequately considered by the legislation and by the environmental agencies, such as petrol filling stations, urban street canyons, arterial roads, road tunnel portals and remote areas characterised by high ozone concentrations. The paper presents specific activities that require additional control by the legislation, due to the associated high potential impacts on the resident population. Such activities are steel production, mechanical-biological treatments of waste, wood burning, poultry breeding, cement production and waste incineration. Finally, the paper presents proposals for a more sustainable management of air quality and human exposure, e.g. improvements in the conventional monitoring approach, stricter or new emission limit values for some activities and precise information to the people on the risks for health and on good practices in indoor environments.
\end{abstract}

Keywords: emissions, legislation, air quality monitoring, dispersion modelling, air pollutants, sustainability.

\section{INTRODUCTION}

Bad air quality is associated with high exposure levels to several macropollutants, such as particulate matter $(\mathrm{PM})$, nitrogen dioxide $\left(\mathrm{NO}_{2}\right)$, carbon monoxide, sulphur dioxide and tropospheric ozone $\left(\mathrm{O}_{3}\right)$. In addition to macropollutants, ambient air is affected by several micropollutants, like volatile organic compounds (VOCs), heavy metals, polycyclic aromatic hydrocarbons (PAHs) and other persistent organic pollutants (POPs), such as polychlorinated dibenzo-p-dioxins (PCDDs), polychlorinated dibenzofurans (PCDFs) and dioxin-like polychlorinated biphenyls (dl-PCBs). Conventionally, air quality monitoring is carried out by local environmental agencies, which verify the compliance with the concentration limit values set by the environmental legislation. Due to the need for ensuring accurate air quality data, the environmental agencies make use of very precise and costly instrumentation hosted in fixed air quality stations. Consequently, the monitoring of population exposure is entrusted to a limited number of fixed stations that, in many cases, may not represent the real exposure of residents or employees. Therefore, for an improved control of emission sources and a global reduction of exposure to air pollutants, it is important to shed a light on the critical aspects of the current regulatory framework and propose solutions to reduce potential underestimated impacts and update the legislation on the basis of new evidences. In the light of the previous considerations, this article aims at highlighting several critical aspects regarding the control of specific activities or contexts that may affect the exposure of the population and induce adverse impacts on health. In this article, the reference regulatory 
framework will be the European legislation. Specifically, this article will critically discuss situations of exposure to air pollutants usually not considered by the environmental legislation. This discussion will touch upon three main aspects: indoor and outdoor quality, and specific activities leading to underestimated emissions or exposure. Wherever possible, practical examples, based on hypothetical case studies, will be presented to better understand the extent of the potential impacts and to underline the needs for focused interventions by public authorities. In addition, this article proposes solutions to the identified problems, to support public bodies and decision makers, in view of a more sustainable management of air quality.

\section{CRITICAL SITUATIONS FOR INDOOR AIR QUALITY}

The time spent in indoor environments and the high concentrations that can be generated by various domestic activities make indoor exposure particularly influent on the total exposure of individuals. The main recognised sources of PM in confined environments are cigarette smoke, biomass burning for cooking and/or heating purposes and cooking itself, regardless of the used energy source [1], [2]. A study that focused on dwellings with smokers showed respectively $650 \%$ and $720 \%$ higher $\mathrm{PM}_{10}$ and $\mathrm{PM}_{2.5}$ concentrations than dwellings without smokers [3]. The presence of wall-to-wall carpeting is an additional source of PM accumulation and consequent release, following vacuum cleaning. A recent study also demonstrated the role of external contributions in determining indoor PM concentrations up to 8 times background outdoor concentrations [4].

Wood burning is a known issue especially in developing countries. A recent review on South Asia reported mean indoor $\mathrm{PM}_{2.5}$ concentrations up to 180 times the World Health Organization standard $\left(25 \mu \mathrm{g} / \mathrm{m}^{3}\right)$, especially where the majority of population relies on traditional biomass stoves [5]. PM emissions and. thus, indoor concentrations and personal exposure strongly depend on the type of stove in use: in rural China, Liu et al. [6] found that the contribution of improved coal stoves and firewood gasifiers to personal $\mathrm{PM}_{2.5}$ exposure was half that of traditional coal stoves. In developed countries, the use of wood stoves has recently increased, boosted by the utilisation of a renewable source and by its lower cost compared to fossil fuels, especially where wood is abundant, like mountainous regions. However, the use of old-type stoves entails higher indoor PM concentrations with respect to outdoors [7]. In addition, the size of the fuel and its moisture have great influence on PM generation. In this sense, the use of dry wood pellets in new stoves is the optimal choice to limit emissions in indoor environments and, meanwhile, outdoors [8]. The use of natural-gas burners or, preferably, electrical or induction hotplates is the best option to reduce PM exposure during cooking. Wood burning is also responsible for the emissions of VOCs, PAHs and dioxin. Among VOCs, benzene plays a major role, being a demonstrated carcinogen for humans [9]. A monitoring campaign carried out in Sweden showed that mean indoor benzene concentrations may double the corresponding outdoor concentrations [10]. Additional contributions to benzene indoor concentration can come from outdoors, following window opening or infiltration of outdoor air. A recent study on school environments in industrial areas showed that mean benzene indoor concentrations may double and triple the concentrations measured in urban and rural schools, respectively [11].

External contributions can have great influence in determining indoor concentrations also in the case of other carcinogenic VOCs, such as formaldehyde and acetaldehyde: in Puertollano (Spain), the mean indoor concentrations of those pollutants were up to five times the respective mean outdoor concentrations [12]. Formaldehyde originates also from carpets, furniture and wood or laminated wood flooring [13]. During the first two weeks from their purchase, it is advisable to avoid placing such housing elements inside the dwellings [14]. 
Indoor concentrations of formaldehyde and other hazardous air pollutants, recently measured at an Australian university, exceeded outdoor concentrations by up to two orders of magnitude [15]. A recent investigation shows that a simple exchange of air may considerably reduce the mean formaldehyde concentration, which passed from $43 \mathrm{ppb}$ to $1 \mathrm{ppb}$ in this specific study [16]. The cooking of animal and vegetable fats and meat is also responsible for the emission of several PAHs [17]. Old-type stoves and fireplaces may also emit dioxin [18], whose formation is favoured by inefficient combustion and by fuels containing traces of chlorine, such as plastics or treated wood.

In addition to being a typical traffic-related pollutant, $\mathrm{NO}_{2}$ is generated by any form of combustion. $\mathrm{NO}_{2}$ emissions in indoor environments are mainly generated by natural-gas burners, fireplaces and old-type wood stoves [19]. The use of hoods may help reducing the contribution of $\mathrm{NO}_{2}$ from natural-gas burners in kitchens [20]. Indoor exposure to $\mathrm{NO}_{2}$, even coming from outside, may be more critical for places where intense physical training is practiced (e.g., gyms and sport centres), due to the high inhalation rate of people practicing sport activities [21].

Carbon dioxide $\left(\mathrm{CO}_{2}\right)$ is not conventionally considered as a local pollutant. However, $\mathrm{CO}_{2}$ is a good indicator of the air exchange rate in indoor environments and, partly, of indoor air quality [22]. In addition, high concentrations of $\mathrm{CO}_{2}$ induce negative effects on humans, such as decrease of attention and productivity, and discomfort eventually. Ensuring a regular ventilation of closed environments, for instance by automatic ventilation systems, allows taking $\mathrm{CO}_{2}$ concentrations back to acceptable levels.

\section{CRITICAL SITUATIONS FOR OUTDOOR AIR QUALITY}

In spite of the progressive decrease in the content of benzene in petrol, road traffic is the sector that most contributes to benzene emissions in Europe [23]. In urban areas, an additional source is represented by petrol filling stations: benzene tends to evaporate from reservoirs and car tanks during refilling, due to its high volatility. A study carried out in 2007 in the Greek city of Ioannina showed that benzene concentrations $>20 \mu \mathrm{g} / \mathrm{m}^{3}$ can be achieved within a radius of 10-20 m from petrol filling stations [24], i.e. more than four times higher than its concentration limit value on annual mean in Europe $\left(5 \mu \mathrm{g} / \mathrm{m}^{3}\right)$. As recently highlighted, petrol filling station, especially if located in urban areas, can also have great influence in determining indoor VOC concentrations [25]. A simple and cost-effective VOC monitoring strategy could rely on diffusive samplers, which can overcome the limitations of fixed air quality stations. The effective reduction of the loss of light hydrocarbons through evaporation can be achieved by the introduction of a small amount of surface-active substances into gasoline [26]. Thus, application of surface-active fuel additives is a perspective method to reduce air pollution by the light hydrocarbons [27]. One legislative measure could be a fuel tax, sensitive to the fuel density [28], [29], directly increasing with increased aromatic content.

The complex morphology of urban areas amplifies the exposure of the population, because such conditions impede an efficient dispersion and dilution of air pollutants. Urban areas usually include channelled streets, known as "urban street canyons". If the ratio between the average height of the lateral buildings and the width of the street is high enough $(>0.65)$, a local helicoidal circulation forms, whose axis is oriented along the street direction. Such circulation may trap air pollutants within the street canyon volume [30]. Since the air quality stations located in an urban area are unlikely to be installed in the several urban street canyons of a town/city, the conventional monitoring approach should be integrated with modelling techniques or unconventional monitoring approaches: diffusive samplers are convenient if the purpose is to evaluate long-term average pollutant concentrations; if peak concentrations 
are important (e.g., in the case of $\mathrm{NO}_{2}$ or $\mathrm{O}_{3}$ ), electrochemical sensors are the most viable option. Dispersion modelling has been widely applied to urban areas. Most of the studies available in the scientific literature focus on road traffic [31], [32]. The role of domestic heating by natural-gas boilers was also recently investigated as another important urban source of air pollution [33]. According to this research, in-canyon concentrations of nitrogen oxides $\left(\mathrm{NO}_{\mathrm{x}}\right)$ may double out-canyon concentrations. Dispersion modelling also allows assessing the benefits expected from the implementation of traffic management policies for environmental purposes. For instance, by allowing only Euro II and newest vehicles (i.e., vehicles produced and commercialised in Europe after 01.01.1997), a 43\% reduction in benzene annual mean concentrations was estimated in the town of Verona (Italy) with respect to the whole vehicle fleet [33].

As a demonstration of the importance of the issues concerning road traffic, in 2005 the World Health Organization highlighted the need for a correct urban planning, aimed at locating school buildings far from arterial roads [34]. Other sensitive places, such as hospitals and rest homes, would require the same level of attention. In addition, urban planning should consider the vicinity to tunnel portals: indeed, the pollutants emitted inside road tunnels concentrate in their proximity [35].

Long-range transport from areas where $\mathrm{O}_{3}$ precursors are emitted is the main reason for $\mathrm{O}_{3}$ accumulation in remote areas [36]. Due to its higher temperature and insolation, the Mediterranean area is the highest contributor to $\mathrm{O}_{3}$ formation in Europe [37]. The main mountain chains (e.g., Balcans, Alps and Pyrenees) prevent the transboundary transport of $\mathrm{O}_{3}$ and, if polluted areas are present, hinder $\mathrm{O}_{3}$ destruction. On mountains, $\mathrm{O}_{3}$ concentrations and altitude are usually positively correlated, both for the almost absence of NO sources and for the frequent phenomena of night-time thermal inversion, which prevent the deposition of $\mathrm{O}_{3}$ from the upper atmospheric layers. In Europe, in 2015, $\mathrm{O}_{3}$ concentrations exceeded the target value for human health protection in $41 \%$ official monitoring stations measuring $\mathrm{O}_{3}$, of which $88 \%$ are located in rural or mountainous areas [36]. Long-term exposure to $\mathrm{O}_{3}$ is associated with a reduction of pulmonary growth and premature mortality, while short-term exposure to $\mathrm{O}_{3}$ peaks may increase the mortality related to cardiorespiratory illness [38]. In spite of the summer peaks of $\mathrm{O}_{3}$ that can be achieved in mountainous regions, where tourism may be highly developed, the level of information to tourists and residents is scarce, especially due to the low number of air quality stations in those contexts. Systematic monitoring of $\mathrm{O}_{3}$ in mountainous regions should be pursued to properly inform tourists on the risks involved in recreational activities when $\mathrm{O}_{3}$ peaks are expected.

\section{CRITICALITIES FROM EMISSIONS OF SOME INDUSTRIAL ACTIVITIES}

\subsection{Diffused emissions from steel-making facilities}

In Europe, according to the last PCDD/F and dl-PCB emission inventory [39], primary steel production (i.e., the sintering process) is the second highest contributor of POPs into the atmosphere, followed by wood burning. Secondary steel production (e.g., the fusion of ferrous scraps by means of the electric arc technology) is the seventh highest contributor of POPs in this rank. During the last two decades, the emissions of POPs and metals from this sector have gradually decreased, thanks to the introduction of the best available techniques (BATs) in the air pollution control lines of steelmaking facilities [40]. The positive effect of BATs is visible also by applying a recent methodology consisting in the characterisation of sediment cores extracted from ponds located in the area affected by the atmospheric deposition of the dusts released by a steelmaking facility. Argiriadis et al. [41] clearly 
detected a decrease in the dl-PCB concentrations in the most superficial layer compared to the deeper ones, which coincides with the documented adoption of the BATs by a secondary steelmaking facility located upwind of the pond of interest.

However, the implementation of BATs does not have any effect on the so-called diffused emissions coming from open-air areas used to stock, load and unload metal slags. The cooling and movement of slags may free dioxin and heavy metals. Since diffused emissions are areal sources at ground level, the vertical velocity of dusts is very low compared to if the emissions were released by a chimney. This behaviour hinders the dilution of emissions. The role of diffused emissions can be quantified by means of dispersion modelling techniques coupled with atmospheric deposition monitoring. The speciation of PCDD/Fs, dl-PCBs and PAHs in environmental matrices is a suitable method to support the identification of the dominant source in the area: indeed, different combustion processes imply different ratios (the so-called "fingerprints") between the concentrations of the single compounds belonging to the same group of chemicals [42]. The influence of diffused emissions emerged in another study on the concentrations of zinc measured on ambient air $\mathrm{PM}_{10}$, being zinc a tracer of secondary steelmaking production [43]. The local impacts of diffused emissions could be significantly reduced if slags were stored in closed environments and if the indoor air was treated and conveyed towards the stacks of a facility.

As mentioned above, steelmaking production generates dioxin emissions. Diet is believed to be responsible for about $90 \%$ human exposure to dioxin [44]. The contamination of the food chain by dioxin mainly originates from the deposition of dioxin to soil. However, the monitoring activities concerning dioxin deposition are numerically lower than those regarding ambient air concentrations. A method to preserve the food chain from dioxin contamination consists in the adoption of a limit value for dioxin deposition above which the commercialisation of locally-grown food (especially milk and dairy products, meat, eggs, fish and cereals) should be forbidden. In this framework, in 2013 an innovative approach was proposed to define an acceptable value of dioxin deposition calibrated on the local diet of an area, in order to preserve the local population from the exposure to doses above the tolerable daily intake proposed by the World Health Organization ( $1 \mathrm{pg}_{\mathrm{TEQ}} / \mathrm{kg} /$ day) [45].

\subsection{Emissions of organic pollutants and odorants from bio-mechanical treatments of waste}

Aerobic mechanical-biological treatments (MBTs) of municipal solid waste (MSW) (i.e., bio-stabilisation, bio-drying and composting) use external air to oxidise the biodegradable fraction of waste. However, the process air enriches with the intermediate compounds generated by waste biodegradation (e.g., ammonia, VOCs and hydrogen sulphide) or with trace compounds already present in the waste (e.g., aromatic VOCs and dioxin) [46]. In the last case, the released compounds may induce adverse effects on health. Some of the released VOCs have also relatively low odour threshold values and, thus, are important from the point of view of odour impacts.

After being stripped by the process air, VOCs can be emitted into the atmosphere from both lateral openings of the facilities and incomplete removal by the air pollution control system. Although the process air is characterised by relatively low VOC concentrations (approximately $10-100 \mathrm{mg} / \mathrm{Nm}^{3}$ ), the airflow rate is relatively high (in the order of 10,000 $\mathrm{Nm}^{3} / \mathrm{h}$ for a medium- or small-size facility). Consequently, the mass flow rate of the released compounds is not negligible (approximately $100-1,000 \mathrm{~g} / \mathrm{h}$ ). The same conclusions holds for the potential presence of dioxin in the input waste, which was estimated at about $20 \mathrm{ng}_{\mathrm{TEQ}} / \mathrm{kg}$ in Italy [47]. As confirmed in a recent experimental study [48], a strategy to reduce VOC and odorant formation during composting consists in the insertion of an anaerobic digestion stage 
upstream of the classical aerobic biodegradation phase. This way, the composting process is carried out on partially stabilised waste.

To further reduce the release of VOCs, the air treatment systems would require improvements. Conventionally, the waste gas coming from an aerobic MBT is treated by an open biofilter, consisting in a rectangular bed filled with natural material (e.g., compost, wood chips, peat or other vegetal materials), which serves as the support for microorganisms that use the organic and inorganic substances present in the process air as the substrate for their growth. Satisfying removal efficiencies require relatively low process-air velocities and, thus, large areas. Due to the low outgoing velocity, biofilters do not ensure a proper dilution and dispersion of the effluent within the low atmosphere, contrarily to the better conditions of dispersion that would be achievable if the effluent was conveyed to a stack. To enhance the atmospheric dispersion of the treated effluent, two options are available: 1) it is possible to cover an open biofilter and convey the effluent to a stack, or 2) biofilters can be replaced with different biofiltration systems, like bio-trickling filters (BTFs). The latter is composed of a column filled with inert material (e.g., plastic rings, plastic or ceramic spheres, lava rocks or shells) that acts as a physical support for the growth of microorganisms, which must be inoculated. A flow of water with nutrients is continuously recirculated on the filtering bed. Since the transversal section of BTFs is significantly lower than biofilters, the outgoing velocity of the effluents from a BTF is much higher. In addition, the effluent can be easily conveyed to a stack.

\subsection{Emissions of particulate matter from poultry breeding farms}

Poultry breeding farms have gained attention in the last years due to their potential role in the release of PM, which is emitted in large amounts because of the lower moisture of poultry manure and the greater mobility of dusts. Dusts are re-suspended by the turbulence induced by the forced aeration applied to control indoor humidity and temperature. The estimation of PM release from the poultry breeding sector is affected by a high level of uncertainty, due to the objective complexity in the quantification of the emissions from single farms. However, the available official data depict a situation that require particular attention. For instance, by an analysis of the emission inventory of an Italian province, poultry breeding farms emit large amount of $\mathrm{PM}_{10}$, quantifiable in $252 \mathrm{t} /$ year [49]. If such data were confirmed, the $\mathrm{PM}_{10}$ emissions from the poultry breeding farms of a province would be higher than those generated by an MSW incinerator by about two orders of magnitude. Furthermore, contrarily to incinerators, the process air from poultry breeding farms is not sent to a stack but exits the building at ground level. Moreover, the process air temperature in breeding farms is far lower than the exhaust gas from the combustion chamber of an incinerator. Therefore, PM dispersion is critical in such contexts. In the light of the previous considerations, poultry breeding farms require specific monitoring and modelling activities, which would allow obtaining an emission factor that could be validated on different farms. It is worth remarking that the PM emitted from farms are mainly composed by bioaerosols, which may induce potential health implications [50]. Thus, if the significant role of poultry breeding farms were confirmed, adequate air treatment systems (e.g., cyclones, bag filters or scrubbers) should be implemented, in combination with conveying the treated air to a stack.

\subsection{Emissions of particulate matter from wood burning}

As mentioned in Section 2, wood burning emits PM, PAHs, VOCs and possibly dioxin, both indoors and outdoors. Therefore, in mountainous and rural areas where domestic stoves are 
widely used, it is crucial to evaluate the contribution of domestic wood burning in terms of PM concentration in ambient air. A convenient method to quantify the contribution of wood burning to $\mathrm{PM}_{10}$ concentration in ambient air consists in the measurement of the concentration of levoglucosan, which is a tracer of cellulose burning. A monitoring campaign carried out during the last decade showed very good correlation between levoglucosan and $\mathrm{PM}_{10}$ [51]. To reduce the contribution of PM from wood burning, the local authorities should make the population aware of the importance of a correct choice of the fuel (preferably dry pellet), should incentivise the renovation of domestic stoves and, wherever possible, invest in biomass-based centralised district heating systems as a replacement of domestic wood burning.

\subsection{Emissions of $\mathrm{NO}_{\mathrm{x}}$ from cement kilns}

Being cement kilns large combustion plants, they are important sources of $\mathrm{NO}_{\mathrm{x}}$. The following hypothetical case study helps understanding the impacts of this sector. In Europe, the $\mathrm{NO}_{\mathrm{x}}$ concentration limit value for the emissions from cement kilns is $500 \mathrm{mg} / \mathrm{Nm}^{3}$ [52] In the hypothesis that the exhaust airflow is $500,000 \mathrm{Nm}^{3} / \mathrm{h}$, the resulting maximum mass flow rate of $\mathrm{NO}_{\mathrm{x}}$ would be $69 \mathrm{~g} / \mathrm{s}$. To estimate how a mass flow rate translates into an ambient air concentration, it is necessary to carry out dispersion simulations. An estimate of the ambient air concentration of a pollutant induced by a specific activity can be calculated, in a simplified way, by using a dilution factor from a similar plant, if the results of a dispersion simulation are available for the latter, and in the hypothesis that the dispersion mechanisms are similar in both cases. The dilution factor may be defined as the ratio between the maximum concentration of a pollutant in ambient air and its mass flow rate at the stack. In this hypothetical case study, a dilution factor of $1.89 \cdot 10^{-7} \mathrm{~s} / \mathrm{m}^{3}$ was assumed, being this the dilution factor of an Italian cement kiln [53]. A cement kiln complying with the emission limit values would induce a maximum $\mathrm{NO}_{\mathrm{x}}$ annual mean concentration of $13 \mu \mathrm{g} / \mathrm{m}^{3}$ in ambient air. However, only $\mathrm{NO}_{2}$ has negative effects on health. The $\mathrm{NO}_{2}$ contribution to $\mathrm{NO}_{\mathrm{x}}$ air concentration can be roughly estimated as $50 \%$ [54]. Thus, the maximum $\mathrm{NO}_{2}$ annual mean concentration would be about $7 \mu \mathrm{g} / \mathrm{m}^{3}$. This contribution would add to the others from other activities in the area and from background concentrations. According to an authoritative cohort study [55], an increase in the long-term exposure to $\mathrm{NO}_{2}$ by $10 \mu \mathrm{g} / \mathrm{m}^{3}$ would imply an $8 \%$ increase in the relative risk for excess mortality. During the authorisation procedure for new plants or during the revision of the authorisations for older plants, it is important to consider the implications on environment and population, to force to adopt the BATs and, if necessary, to set restrictive limits to the exhaust airflow rate.

\subsection{The potential role of chromium VI from waste incineration}

The introduction of the BATs and the more and more restrictive limit values that have been imposed over the years have led to considerable reductions of the impacts of incinerators on public health [56]. In addition, the exhaust airflow rate of medium-size MSW incinerators is generally lower than medium-size cement kilns. However, the European legislation has a critical point regarding the emission limit values of heavy metals. With the exception of mercury, which is regulated by a specific limit value, the remaining metals are regarded as groups. Among these metals, arsenic, cadmium, chromium VI and nickel are demonstrated carcinogens. Theoretically, an incinerator that complies with the European Union regulatory limit values [52] could emit cadmium and chromium VI with concentrations of 0.05 and 0.5 $\mathrm{mg} / \mathrm{Nm}^{3}$, respectively. As an example, if the dilution factor assumed in the case of the 
hypothetical cement kiln presented in Section 4.5 were used $\left(1.89 \cdot 10^{-7} \mathrm{~s} / \mathrm{m}^{3}\right)$ and if the exhaust airflow rate were $100,000 \mathrm{Nm}^{3} / \mathrm{h}$, the corresponding maximum ambient air concentrations of cadmium and chromium VI would be 0.2 and $2.0 \mathrm{ng} / \mathrm{m}^{3}$, respectively. The United States Environmental Protection Agency (US EPA) has continuously updated the socalled inhalation unit risk (IUR) values [57], which are toxicity factors that can be used to estimate the cancer risk related to exposure to a specific pollutant. The IUR of a pollutant is defined as the excess cancer risk related to a mean continuative exposure to $1 \mu \mathrm{g} / \mathrm{m}^{3}$ during a lifetime. The following IUR values are proposed for cadmium and chromium VI, respectively: $1.8 \cdot 10^{-3}$ and $1.2 \cdot 10^{-2}$. Consequently, following continuative exposure over the whole life, the resulting cancer risk would exceed the acceptable value by one order of magnitude. This would be certainly an extreme case, both because the newest incinerators are able to ensure stack concentrations far lower than the limit values and because cadmium and chromium VI do not represent $100 \%$ of the metals included in the respective groups. However, by a monitoring campaign on state-of-the-art incinerators carried out in Italy [58], total chromium resulted as the most abundant metal in its group. Therefore, the authorisation procedure to the emissions from an incinerator should contain a specific limit value for total chromium above which chromium speciation should be investigated.

\section{CONCLUSIONS}

This paper highlighted some uncontrolled situations of exposure and incongruities between the European environmental legislation in terms of air pollution and the potential impacts that different kinds of activities may cause even when complying with the legislation. The conventional monitoring approach is not able to ensure adequate control of human exposure in several hotspots (urban street canyons, petrol filling stations, tunnel portals, remote areas, areas affected by dioxin deposition). Unconventional monitoring methods (diffusive samplers, electrochemical sensors, levoglucosan sampling, deposition and sediment core monitoring with POP speciation) and dispersion modelling can overcome such limitations and should be routinely used by the environmental agencies. The latter should also force specific industrial sectors (steelmaking plants, MBTs of MSW and poultry breeding farms) to convey diffused emissions. Technical expedients (e.g., the introduction of an AD stage in the composting process), a correct urban planning (near busy roads or tunnel portals), strategic energy plans (e.g., centralised district heating in replacement of domestic wood burning) and traffic management policies (in the case of urban street canyons and arterial roads) should become compulsory to avoid criticalities. The environmental agencies should also improve the communication of risks (in touristic remote areas) and of good practices (in indoor environments) to people and should possibly incentivise the replacement of old-type stoves with new ones. Finally, cement kilns and incinerators require stricter regulations, respectively on the authorised airflow rate and on chromium emissions.

\section{ACKNOWLEDGEMENT}

The authors wish to thank the Health Authority of Verona (USSL 20) for the financial support to a part of this research.

\section{REFERENCES}

[1] He, C., Morawska, L., Hitchins, J. \& Gilbert, D., Contribution from indoor sources to particle number and mass concentrations in residential house. Atmospheric Environment, 38, pp. 3405-3415, 2004.

[2] Schiavon, M., Rada, E.C., Ragazzi, M., Antognoni, S. \& Zanoni, S., Domestic activities and PM generation: A contribution to the understanding of indoor sources of 
air pollution. International Journal of Sustainable Development and Planning, 10(3), pp. 347-360, 2014

[3] Slezakova, K., Castro, D., Pereira, M.C., Morais, S., Delerue-Matos, C. \& AlvimFerraz, M.C., Influence of tobacco smoke on carcinogenic PAH composition in indoor $\mathrm{PM}_{10}$ and $\mathrm{PM}_{2.5}$. Atmospheric Environment, 43, pp. 6376-6382, 2009.

[4] Cleary, E., Asher, M., Olawoyin, R. \& Zhang, K., Assessment of indoor air quality exposures and impacts on respiratory outcomes in River Rouge and Dearborn, Michigan. Chemosphere, 187, pp. 320-329, 2017.

[5] Junaid, M., Syed, J.H., Abbasi, N.A., Hashmi, M.Z., Malik, R.N. \& Pei, D.-S., Status of indoor air pollution (IAP) through particulate matter (PM) emissions and associated health concerns in South Asia. Chemosphere, 191, pp. 651-663, 2018.

[6] Liu, W. et al., Air pollution and inhalation exposure to particulate matter of different sizes in rural households using improved stoves in central China. Journal of Environmental Sciences, 63, pp. 87-95, 2018.

[7] Molnár, P., Gustafson, P., Johannesson, S., Boman, J., Barregård, L. \& Sällsten, G., Domestic wood burning and $\mathrm{PM}_{2.5}$ trace elements: Personal exposures, indoor and outdoor levels. Atmospheric Environment, 39, pp. 2643-2653, 2005.

[8] Carvalho, R.L., Jensen, O.M. \& Tarelho, L.A.C., Mapping the performance of woodburning stoves by installations worldwide. Energy and Buildings, 127, pp. 658-679, 2016.

[9] IARC Monographs, Classifications, International Agency for Research on Cancer. http://monographs.iarc.fr/ENG/Classification/latest_classif.php. Accessed on: 7 Dec. 2017.

[10] Gustafson, P., Barregard, L., Strandberg, B. \& Sällsten, G., The impact of domestic wood burning on personal, indoor and outdoor levels of 1,3-butadiene, benzene, formaldehyde and acetaldehyde. Journal of Environmental Monitoring, 9(1), pp. 2332, 2007.

[11] Villanueva, F., Tapia, A.. Lara, S. \& Amo-Salas, M., Indoor and outdoor air concentrations of volatile organic compounds and $\mathrm{NO}_{2}$ in schools of urban, industrial and rural areas in Central-Southern Spain. Science of the Total Environment, 622-623, pp. 222-235, 2018.

[12] Villanueva, F., Tapia, A., Amo-Salas, M., Notario, A., Cabañasa, B. \& Martínez, E., Levels and sources of volatile organic compounds including carbonyls in indoor air of homes of Puertollano, the most industrialized city in central Iberian Peninsula. Estimation of health risk. International Journal of Hygiene and Environmental Health, 218, pp. 522-534, 2015.

[13] Pierce, J.S. et al., An assessment of formaldehyde emissions from laminate flooring manufactured in China. Regulatory Toxicology and Pharmacology, 81, 20-32, 2016.

[14] Böhm, M., Salem, M.Z.M. \& Srba, J., Formaldehyde emission monitoring from a variety of solid wood, plywood, blockboard and flooring products manufactured for building and furnishing materials. Journal of Hazardous Materials, 221-222, pp. 6879, 2012.

[15] Goodman, N.B., Wheeler, A.J., Paevere, P.J., Selleck, P.W., Cheng, M. \& Steinemann, A., Indoor volatile organic compounds at an Australian university. Building and Environment, in press.

[16] Al-Hemoud, A., Indoor air quality guidelines and investigation of the effect of door opening and closing on the concentrations of VOCs, formaldehyde, and $\mathrm{NO}_{2}$ in office buildings during three periods (pre, post-, and summer). Building and Environment, in press. 
[17] Abdullahi, K.L., Delgado-Saborit, J.M. \& Harrison, R.M., Emissions and indoor concentrations of particulate matter and its specific chemical components from cooking: a review. Atmospheric Environment, 71, pp. 260-294, 2013.

[18] Kerimray, A., Rojas-Solórzano, L., Amouei Torkmahalleh, M., Hopke, P.K. \& O'Gallachóir, B.P., Coal use for residential heating: Patterns, health implications and lessons learned. Energy for Sustainable Development, 40, pp. 19-30, 2017.

[19] Raw, G.J., Coward, S.K., Brown, V.M. \& Crump, D.R., Exposure to air pollutants in English homes. Journal of Exposure Analysis and Environmental Epidemiology, 14, pp. S85-94, 2004.

[20] Singer, B.C., Zarin Pass, R., Delp, W.W., Lorenzetti, D.M. \& Maddalena, R.L., Pollutant concentrations and emission rates from natural gas cooking burners without and with range hood exhaust in nine California homes. Building and Environment, 122, pp. 215-229, 2017.

[21] Andrade, A. \& Dominski, F.H., Indoor air quality of environments used for physical exercise and sports practice: Systematic review. Journal of Environmental Management, 206, pp. 577-586.

[22] Ragazzi, M., Rada, E.C., Zanoni, S., Passamani, G. \& Dalla Valle, L., Particulate matter and carbon dioxide monitoring in indoor places. International Journal of Sustainable Development and Planning, 12(6), pp. 1032-1042, 2017.

[23] Air quality in Europe, 2014 report, European Environment Agency. https://www.eea.europa.eu/publications/air-quality-in-europe-2014. Accessed on: 10 Dec. 2017.

[24] Karakitsios, S.P., Delis, V.K., Kassomenos, P.A. \& Pilidis, G.A., Contribution to ambient benzene concentrations in the vicinity of petrol stations: Estimation of the associated health risk. Atmospheric Environment, 41, pp. 1889-1902, 2007.

[25] Hicklin, W., Farrugia, P.S. \& Sinagra, E., Investigations of VOCs in and around buildings close to service stations. Atmospheric Environment, 172, pp. 93-101, 2018.

[26] Magaril, E. \& Magaril, R., Improving the environmental and performance characteristics of vehicles by introducing the surfactant additive into gasoline. Environmental Science and Pollution Research, 23(17), pp. 17049-17057, 2016.

[27] Magaril, E., Increasing the efficiency and environmental safety of vehicle operation through improvement of fuel quality. International Journal of Sustainable Development and Planning, 10(6), pp. 880-893, 2015.

[28] Magaril, E., Improvement of the environmental and operational characteristics of vehicles through decreasing the motor fuel density. Environmental Science and Pollution Research, 23(7), 6793-6802, 2016.

[29] Golubeva, A. \& Magaril, E., Environmental tax as an instrument of economic stimulation to improve the quality of motor fuels. WIT Transactions on Ecology and the Environment, vol. 192, WIT Press: Southampton and Boston, pp. 149-159, 2015.

[30] Oke, T.R., Street design and urban canopy layer climate. Energy and Buildings, 11, pp. 103-111, 1988.

[31] Gallagher, J., Gill, L.W. \& McNabola, A., The passive control of air pollution exposure in Dublin, Ireland: a combined measurement and modelling case study. Science of the Total Environment, 458-460, pp. 331-343, 2013.

[32] Borge, R. et al., Emission inventories and modeling requirements for the development of air quality plans. Application to Madrid (Spain). Science of the Total Environment, 466-467, pp. 809-819, 2014 
[33] Schiavon, M. et al., Assessing the air quality impact of nitrogen oxides and benzene from road traffic and domestic heating and the associated cancer risk in an urban area of Verona (Italy). Atmospheric Environment, 120, pp. 234-243, 2015.

[34] Krzyzanowski, M., Kuna-Dibbert, B. \& Schneider, J., Health effects of transportrelated air pollution, World Health Organization: Copenhagen, 2005.

[35] Bari, S. \& Naser, J., Simulation of airflow and pollution levels caused by severe traffic jam in a road tunnel. Tunnelling and Underground Space Technology, 25, pp. 70-77, 2010.

[36] Air quality in Europe, 2017 report, European Environment Agency. https://www.eea.europa.eu/publications/air-quality-in-europe-2017. Accessed on: 10 Dec. 2017.

[37] Querol, X. et al., On the origin of the highest ozone episodes in Spain. Science of the Total Environment, 571, pp. 379-389, 2016.

[38] Chen, T.M., Gokhale, J., Shofer, S. \& Kuschner, W.G., Outdoor air pollution: ozone health effects. The American Journal of the Medical Sciences, 333, pp. 244-248, 2007.

[39] Quaß, U., Fermann, M. \& Broker, G., The European dioxin air emission inventory project - final results. Chemosphere, 54, pp. 1319-1327, 2004.

[40] Rada, E.C. et al., PCDD/Fs in the soils in the province of Trento: 10 years of monitoring. Environmental Monitoring and Assessment, 187, pp. 1-12, 2015.

[41] Argiriadis, E. et al., Assessing the influence of local sources on POPs in atmospheric depositions and sediments near Trento (Italy). Atmospheric Environment, 98, pp. 3240, 2014.

[42] Rada, E.C., Ragazzi, M. \& Schiavon, M., Assessment of the local role of a steel making plant by POPs deposition measurements. Chemosphere, 110, pp. 53-61, 2014.

[43] Rada, E.C. et al., Characterization of metals in air and soil near a steel making plant in the North part of Italy. Management of Environmental Quality: An International Journal, 27, pp. 441-451, 2016.

[44] Sasamoto, T. et al., Estimation of 1999-2004 dietary daily intake of PCDDs, PCDFs and dioxin-like PCBs by a total diet study in metropolitan Tokyo, Japan. Chemosphere, 64, pp. 634-641, 2006.

[45] Schiavon, M., Ragazzi, M. \& Rada, E.C., A proposal for a diet-based local PCDD/F deposition limit. Chemosphere, 93, pp. 1639-1645, 2013.

[46] Schiavon, M., Torretta, V., Rada, E.C. \& Ragazzi, M., State of the art and advances in the impact assessment of dioxins and dioxin-like compounds. Environmental Monitoring and Assessment, 188(1), p. 57, 2016.

[47] Rada, E.C., Ragazzi, M., Panaitescu, V. \& Apostol, T., The role of bio-mechanical treatments of waste in the dioxin emission inventories. Chemosphere, 62, 404-410, 2006.

[48] Schiavon, M. et al., Characterisation of volatile organic compounds (VOCs) released by the composting of different waste matrices. Environmental Pollution, 231, pp. 845$853,2017$.

[49] INEMAR VENETO 2013, Regional Atmospheric Emission Inventory in Veneto Region, Environmental Protection Agency of Veneto (in Italian), 2013. http://213.217. 132.90/inemar/webdata/main.seam. Accessed on: 14 Dec. 2017.

[50] Seedorf, J., An emission inventory of livestock-related bioaerosols for Lower Saxony, Germany. Atmospheric Environment, 38, pp. 6565-6581, 2004.

[51] Rada, E.C., Ragazzi, M. \& Malloci, E., Role of levoglucosan as a tracer of wood combustion in an alpine region. Environmental Technology, 33(9), pp. 989-994, 2012. 
[52] Directive 2010/75/EU of the European Parliament and of the Council of 24 November 2010 on industrial emissions (integrated pollution prevention and control). Official Journal of the European Union L 334/17, 2010.

[53] Dispersion modelling of the air pollutants emitted by the cement kiln of Industria Cementi Giovanni Rossi SpA in the municipality of Pederobba (Treviso), Environmental Protection Agency of Veneto (in Italian). http:/www.arpa.veneto.it/ arpav/chi-e-arpav/file-e-allegati/dap-treviso/cementi-rossi/modellistica_di_ dispersion_di_inquinanti_2009.pdf. Accessed on: 14 Dec. 2017.

[54] Düring, I., Bächlin, W., Ketzel, M., Baum, A., Friedrich, U. \& Wurzler, S., A new simplified $\mathrm{NO} / \mathrm{NO}_{2}$ conversion model under consideration of direct $\mathrm{NO}_{2}$-emissions. Meteorologische Zeitschrift, 20(1), pp. 67-73, 2009.

[55] Raaschou-Nielsen, O. et al., Traffic air pollution and mortality from cardiovascular disease and all causes: a Danish cohort study. Environmental Health, 11, p. 60, 2012.

[56] Schecter, A., Papke, O., Ball, M., Lis, A. \& Brandt-Rauf, P., Dioxin concentrations in the blood of workers at municipal waste incinerators. Occupational and Environmental Medicine, 52, pp. 385-387, 1995.

[57] Guidelines for Carcinogenic Risk Assessment, U.S. Environmental Protection Agency. www3.epa.gov/airtoxics/cancer_guidelines_final_3-25-05.pdf. Accessed on: 15 Dec. 2017.

[58] Emissions from state-of-the-art incinerators, Analysis of the Frullo plant, EmiliaRomagna Region (in Italian). https://www.arpae.it/cms3/documenti/moniter/quaderni/ 03_emissioni.pdf. Accessed on: 20 Dec. 2017. 